\title{
Assessment of Intravitreal Injection Training among U.S.-Based Ophthalmology Residents
}

\author{
Jacob J. Liechty, $\mathrm{MS}^{1}$ Michael J. Wilkinson, MD ${ }^{2}$ Esther M. Bowie, MD \\ 1 Pennsylvania State College of Medicine, Hershey, Pennsylvania \\ ${ }^{2}$ Department of Ophthalmology, Pennsylvania State College of \\ Medicine, Hershey, Pennsylvania

\begin{abstract}
Address for correspondence Esther M. Bowie, MD, Department of Ophthalmology, Pennsylvania State College of Medicine, 500 University Drive, Hershey, PA 17033

(e-mail: ebowie@pennstatehealth.psu.edu).
\end{abstract}

J Acad Ophthalmol 2019;11:e43-e49.

\begin{abstract}
Keywords

- resident

- training

- intravitreal

- retina

Purpose To describe the intravitreal injection training of ophthalmology residents in the United States in 2018.

Design Cross-sectional survey.

Methods An anonymous, 29-question, internet-based survey was emailed to 119 ophthalmology residency program directors with the instructions to forward the survey to their ophthalmology residents.

Results A total of 117 ophthalmology residents (7.89\%) responded to the survey. The majority of residents stated that their intravitreal injection training began during their first year of ophthalmology training, PGY 2 year, (92.3\%). The majority of residents performed at least 25 injections per year (78.6\%). All residents use antiseptic on the conjunctiva prior to the injection, $94 \%$ use a lid speculum, and $84.6 \%$ avoided talking in the procedure room. Most injections are performed with gloves (83.8\%). A minority of residents stated that they are trained to use povidone-iodine on the eyelids prior to performing an injection (45.3\%). Only $6.0 \%$ of residents claimed to use postinjection antibiotic drops. Performance of bilateral, simultaneous intravitreal injections was split with nearly half of residents not being trained in this method (47.9\%).

Conclusion Ophthalmology residents from across the country experience a variety of different injection protocols when being trained on how to perform intravitreal injections. Conjunctival antisepsis has reached a clear consensus while topics such as simultaneous, bilateral injections and eyelid antisepsis are still uncertain among the resident community.
\end{abstract}

Intravitreal injections have been commonplace in ophthalmology clinics for over a decade and yet there remains a need for standardization of protocols surrounding the administration of these injections. Having standardized protocols provides a consistent framework for medical training and improves the quality of health care delivered. It will also strengthen the medico-legal aspects of the health care provided. In 2001 there were 4,215 intravitreal injections performed across the entire United States. ${ }^{1}$ Ten years later that number rose to 2.5 million and it has only continued to grow since then. ${ }^{2}$ Complications, though rare, associated with intravitreal injections include endophthalmitis, retinal tear and detachment, cataracts, and ocular hypertension. ${ }^{3-7}$ Traditionally, intravitreal injections are performed by retina specialists and retina fellows; however, their prevalence in practice has led to ophthalmology residents being trained on injection techniques. ${ }^{8}$ Prior studies have already reported on the practice patterns among retina specialists in several countries. ${ }^{9-12}$ In 2014, Avery et al published updated recommendations for intravitreal injections which were soon followed by the American Academy of Ophthalmology (AAO) consensus statement in 2015. ${ }^{13,14}$ The aim of this study is to determine the training patterns of ophthalmology residents performing intravitreal injections and to compare received

August 26, 2018 accepted after revision April 8, 2019
DOI https://doi.org/

10.1055/s-0039-1688912. ISSN 2475-4757.
Copyright $\odot 2019$ by Thieme Medical Publishers, Inc., 333 Seventh Avenue, New York, NY 10001, USA. Tel: +1(212) 584-4662.
License terms

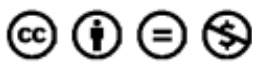


these patterns with the practice patterns of retina specialists, guidelines provided by Avery et al in 2014, and the AAO consensus statement in 2015.

\section{Methods}

Ophthalmology residency program directors from each of the 119 ophthalmology residency training programs accredited by the Accreditation Council for Graduate Medical Education (ACGME) were contacted via email with a link to an anonymous, 29 question, internet-based survey. The questions were created by a faculty member and medical student of Penn State College of Medicine. Historical surveys in conjunction with clinical insight were used to determine the specifics of each question. The survey was created by adopting questions from prior surveys that were already validated and published..$^{9-12}$ The new collection of questions was then reviewed by a faculty/medical student team to assess accuracy and relevance. A complete list of the survey questions can be found in -Appendix A. The residency directors were asked to disseminate the survey link to the residents at their respective programs. The survey link was first sent out on April 17, 2018 with two reminder emails that followed in the next month.

\section{Results}

By June 18, 2018, 117 residents (7.89\%) completed the survey. All respondents that completed the survey stated that they are trained in how to preform intravitreal injections during residency. - Fig. 1 shows the regional representation of residents. The majority of residents that responded are being trained in the South and Midwest. Most residents performed injections at a university or veterans medical center (-Fig. 2). One-hundred and eight (92.3\%) residents stated that they began performing injections during their PGY 2 year. Only seven $(6.0 \%)$ and two (1.7\%) residents stated that they did not begin performing injections until the PGY 3 and PGY 4 years,

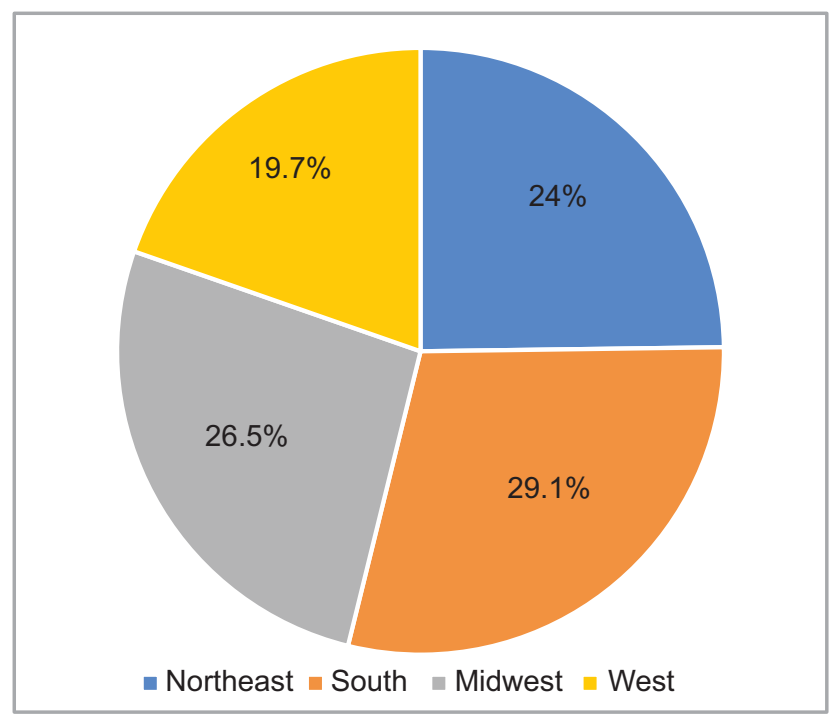

Fig. 1 Regional representation of residents.

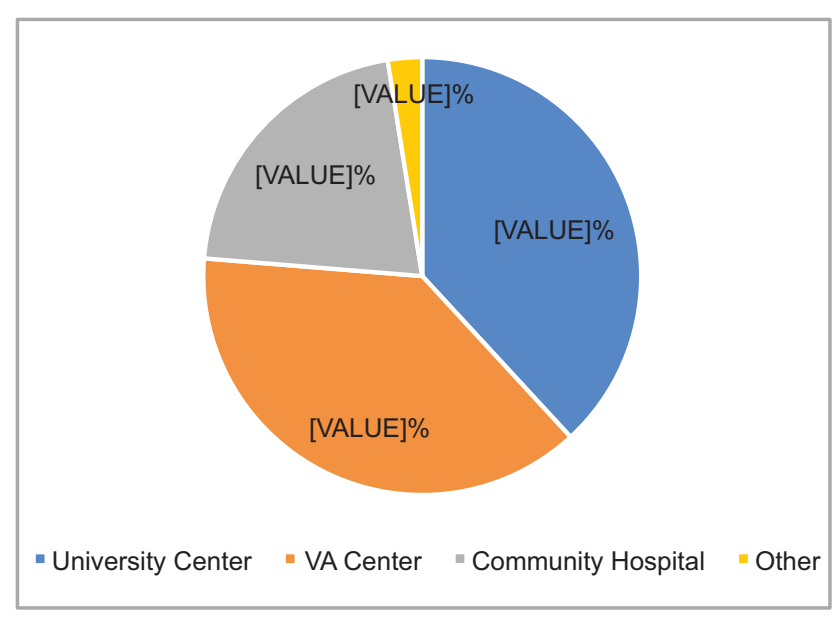

Fig. 2 Breakdown of resident training environments.

respectively. The majority of residents (43.6\%) performed greater than 50 injections per year. Thirty five percent performed 25 to 50 injections per year, 19.7\% performed 10 to 25 injections per year, and $1.7 \%$ performed less than 10 injections per year (-Fig. 3).

\section{Preinjection Considerations}

- Table 1 shows the results of this study compared with prior studies, along with the recommendations offered by the 2014 expert panel and the 2015 AAO consensus statement. ${ }^{13,14}$ The majority of residents, 91 (77.8\%), routinely dilate the eye that is being injected prior to the injection. Ninety-eight (83.8\%) residents wear gloves when performing injections. Of the 98 residents that wear gloves, 57 (58.2\%) use sterile gloves and 41 (41.8\%) use clean gloves. Ninety-nine (84.6\%) residents stated that they are trained to avoid talking in the procedure room during injections. The majority of residents, 110 (94.0\%) and 111 (94.9\%), use an eyelid speculum and povidone-iodine preinjection on the conjunctiva, respectively. Six (5.1\%) residents use sodium hypochlorite as conjunctival antiseptic instead of betadine. A small number of residents, $6.0 \%$, use postinjection prophylactic antibiotics.

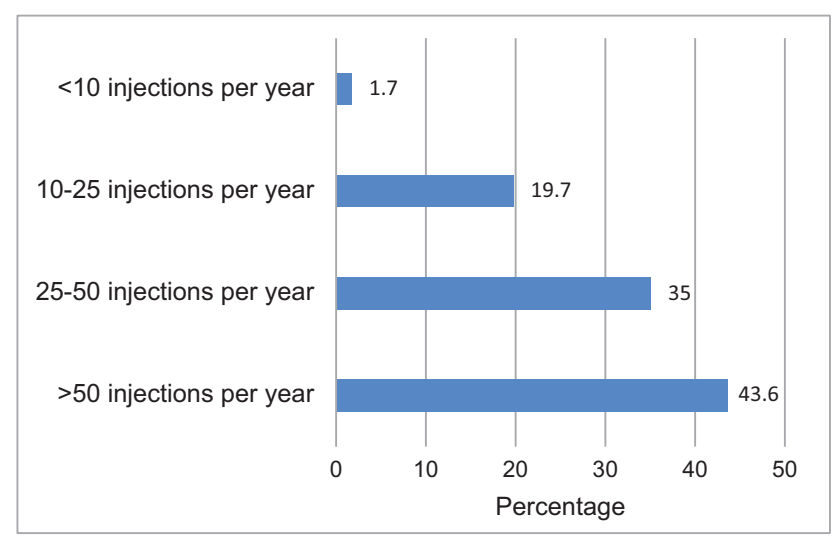

Fig. 3 Average number of intravitreal injections performed per residency year. 
Table 1 Comparison of IVI techniques between this study and prior studies

\begin{tabular}{|c|c|c|c|c|c|}
\hline IVI technique & $\begin{array}{l}\text { U.S. residents } \\
2018(N=117)\end{array}$ & $\begin{array}{l}\text { U.S. } \\
\text { physicians } \\
2010^{9}\end{array}$ & $\begin{array}{l}\text { Canadian } \\
\text { physicians } \\
2012^{10}\end{array}$ & $\begin{array}{l}\text { Recommended } \\
\text { by } 2014 \\
\text { guidelines }^{13}\end{array}$ & $\begin{array}{l}\text { Recommended by } \\
2015 \text { consensus } \\
\text { statement }^{14}\end{array}$ \\
\hline Pupil dilation & $78 \%(91)$ & - & $83 \%$ & Optional & Yes \\
\hline Gloves & $84 \%(98)$ & $58 \%$ & $39 \%$ & Yes & - \\
\hline Sterile drape & $10 \%(12)$ & $12 \%$ & $9 \%$ & No & - \\
\hline Mask & $34 \%(40)$ & $29 \%$ & - & Yes & - \\
\hline Lid speculum & $94 \%(110)$ & $92 \%$ & $91 \%$ & Optional & - \\
\hline Conjunctival povidone-iodine & $95 \%(111)$ & $100 \%$ & $100 \%$ & Yes & Yes \\
\hline Conjunctival sodium hypochlorite & $5 \%(6)$ & $0 \%$ & $0 \%$ & - & - \\
\hline Periocular povidone-iodine & $45 \%(63)$ & - & $48 \%$ & Optional & - \\
\hline Preinjection antibiotics & $10 \%(12 /)$ & & & No & No \\
\hline Measured injection site & $91 \%(106)$ & $56 \%$ & $55 \%$ & - & - \\
\hline Optic nerve perfusion & $77 \%(89)$ & $72 \%$ & $48 \%$ & Yes & Yes \\
\hline Postinjection antibiotics & $6 \%(7)$ & $81 \%$ & $20 \%$ & No & No \\
\hline Bilateral IVI & $52 \%(61)$ & $46 \%$ & $57 \%$ & Optional & - \\
\hline
\end{tabular}

Abbreviation: IVI, intravitreal injection.

\section{Injection Technique}

- Table 2 shows ophthalmology resident injection technique preferences. Sixty-nine (59.0\%) of residents are trained to prefer a superotemporal injection site while forty-eight (41.0\%) are trained to inject inferotemporally. The majority of residents, 106 (90.6\%), use measurements to determine the location of the injection site. Of these 106 residents, 77 (72.6\%) use calipers and 26 (24.5\%) use a tuberculin syringe. One-

Table 2 Other injection techniques taught to U.S. ophthalmology residents

\begin{tabular}{|l|l|}
\hline IVI technique & $\begin{array}{l}\text { U.S. residents } \\
2018(N=117)\end{array}$ \\
\hline Clean gloves & $35 \%(41)$ \\
\hline Sterile gloves & $49 \%(57)$ \\
\hline Avoid talking & $85 \%(99)$ \\
\hline Superotemporal injection site & $59 \%(69)$ \\
\hline Inferotemporal injection site & $41 \%(48)$ \\
\hline Use calipers to measure injection site & $66 \%(77)$ \\
\hline $\begin{array}{l}\text { Use TB syringe to measure } \\
\text { injection site }\end{array}$ & $22 \%(26)$ \\
\hline $\begin{array}{l}\text { Use other device to measure } \\
\text { injection site }\end{array}$ & $2.6 \%(3)$ \\
\hline $\begin{array}{l}\text { 30-gauge needle for } \\
\text { anti-VEGF injections }\end{array}$ & $91 \%(106)$ \\
\hline $\begin{array}{l}\text { 27-gauge needle for } \\
\text { triamcinolone injections }\end{array}$ & $71 \%(77)$ \\
\hline Postinjection gross visual acuity & $59 \%(69)$ \\
\hline Postinjection optic nerve visualization & $14 \%(16)$ \\
\hline Postinjection IOP measurement & $3.4 \%(4)$ \\
\hline
\end{tabular}

Abbreviations: IOP, intraocular pressure; IVI, intravitreal injection; TB, tuberculin; VEGF, vascular endothelial growth factor. hundred and six (90.6\%) residents use a 30- and 27-gauge needle when performing injections with antivascular endothelial growth factor drugs and triamcinolone acetonide, respectively. Twenty-two (19.0\%) residents stated that they are trained to consider the speed of the jet of fluid during the injection. Of these residents, 11 (50.0\%) stated that they are trained to inject slowly and 11 (50.0\%) stated that they are trained to inject quickly.

\section{Postinjection Considerations}

Most residents, 89 (76.7\%), assess postinjection optic nerve perfusion. Of these residents, 69 (77.5\%) use visual acuity and a few, 16 (18.0\%) and 4 (4.5\%), are trained to use visualization of the optic disc and measurement of intraocular pressure (IOP), respectively. These results are summarized in - Table 2 .

\section{Discussion}

Our study is the first to report the practice patterns of intravitreal injections among residents trained in the United States. The rate of resident-performed injections has continued to rise over the past 10 years. In 2006, a survey of program directors found that $75 \%$ of the program directors that responded were having their residents perform fewer than 10 injections prior to graduating. ${ }^{8}$ Resident responders to this survey show that $78.6 \%$ are performing, on average, at least 25 of these injections each year of their training. This survey also demonstrates that there are discrepancies among the intravitreal injection training techniques of U.S.based ophthalmology residents and retina specialists. Prior studies looked at practice patterns among retina providers but, until now, had never addressed the potential cause of these discrepancies which may lie in the training received during residency. The largest of these studies was conducted in 2010, prior to new guideline recommendations 
that were published in 2014 and the 2015 AAO consensus statement. $9,13,14$ It is important to determine whether or not these new recommendations have begun to affect the way in which ophthalmology residents are currently being trained.

\section{Preinjection Considerations}

Ninety-one (77.8\%) residents stated that they are trained to routinely dilate the eye that is to be injected. This number is consistent with reports from Canadian physicians in $2012 .{ }^{11}$ The 2014 guidelines suggested this may be optional and the 2015 AAO consensus statement suggested using mydriatics before injections. ${ }^{13,14}$ There is no clear consensus on whether or not patients need to be dilated. The survey did not distinguish between visits to make the diagnosis and injection visits; therefore, we are unable to determine from this study if patients were dilated for a planned injection visit. Dilation may be done as a part of the routine clinic visit to make the diagnosis, find other retina problems, as well as to examine postinjection optic nerve perfusion and complications. Our survey found that 57 (48.7\%) residents are trained to use sterile gloves, which reflects a $15.7 \%$ increase when compared with providers surveyed in 2010 . The use of gloves (sterile or unsterile) does not impact the overall rate of postinjection endophthalmitis. ${ }^{15,16}$ Glove use may be varied based on the culture of the practice. Ninety-four percent of residents are trained to use a lid speculum which is consistent with the 2014 guidelines. ${ }^{13}$ The guidelines recommend the use of some form of lid retraction if a lid speculum is not utilized. ${ }^{13}$ Our study specifically asked about lid speculum use so we do not know if any other method of lid retraction was used by the remaining $6 \%$ of residents. One of the new recommendations that came with the 2014 guidelines was to either utilize a surgical face mask or minimize talking during the in-office procedures. ${ }^{13}$ This recommendation is based off of the findings that endophthalmitis secondary to intravitreal injection has a disproportionately higher rate of streptococcus isolates when compared to endophthalmitis secondary to intraocular surgery. ${ }^{17-19}$ This survey found that this new recommendation has been heeded as $84.6 \%$ of residents stated that they are trained to avoid talking while performing injections. The 2014 panel did not recommend the use of a sterile drape as evidence showed that its use did not affect the overall rate of postinjection endophthalmitis. ${ }^{13,16,20}$ Residency training is consistent with this recommendation as only $10.3 \%$ of residents stated that they are trained to use a sterile drape. One of the most notable differences between the U.S.-based providers that were surveyed in 2010 and current U.S. residents is that $34 \%$ of providers claimed to use prophylactic, preinjection, topical antibiotics, while only $10.3 \%$ of current residents are trained to maintain this practice. This is consistent with numerous studies which found that not only did preinjection antibiotics provide no real benefit but may actually pose some harm in the form of promoting antibiotic-resistant bacteria. $^{16,21-25}$ This discrepancy between our survey and the 2010 U.S. provider survey is most likely because the U.S. provider survey was done before the antibiotic recommendations were changed.

\section{Injection Technique}

This survey found that $90.6 \%$ of residents are trained to measure the distance from the limbus to the injection site with the majority of these residents (72.6\%) utilizing calipers to make the measurement. This is in stark contrast to what was found when active providers were surveyed in 2010. At that time only $56 \%$ of retina specialists claimed to measure the distance between the limbus and their injection site. ${ }^{9}$ It is possible that calipers are used preferentially in training because it provides a more exact measurement. Retina physicians with years of experience may no longer feel the need to measure prior to preforming their injections. Another difference between providers in 2010 and current residents is the consideration of the speed of the actual injection. In 2010, 59\% of surveyed physicians claimed to consider the speed at which they did their injections. ${ }^{9}$ This survey found that only $19 \%$ of current residents are trained to make this same consideration. In 2010, among physicians that considered injection speed, $76 \%$ chose to inject quickly. This survey found that the speed of injection was equivocal. Guidelines in 2004 recommended injecting slowly to avoid excessive drug dispersion. ${ }^{26}$ New evidence, however, indicates that injection speed makes no difference in drug dispersion. ${ }^{27}$ The discrepancy in the literature may be the reason for our equivocal survey results.

\section{Postinjection Technique}

This survey found that $76.7 \%$ of residents are trained to assess postinjection optic nerve perfusion. This is similar to the $72 \%$ of practicing retina specialists that assess postinjection optic nerve perfusion in $2010 .{ }^{9}$ It is difficult to directly compare the methods for assessing optic nerve perfusion between 2010 and now because in 2010 the respondents were offered a choice that combined more than one method whereas this survey only allowed respondents to select one choice. In spite of that, it is fairly certain that measuring IOP to assess optic nerve perfusion is less common now than it was then. Only $4.5 \%$ of residents stated that they are trained to utilize this method of assessment, while $15 \%$ of retinal specialists selected this as their sole method of assessment in 2010. ${ }^{9}$ The new 2014 guidelines suggest that IOP should be checked prior to administration of an injection but give no recommendation on IOP versus gross visual acuity for postinjection assessment. ${ }^{13}$ The use of postinjection prophylactic antibiotics is another area where new guidelines have made a clear impact. The 2010 survey of U.S.-based retinal specialists found that $81 \%$ used postinjection antibiotics. This survey found that only $6.0 \%$ of residents are being trained to continue this practice. The 2014 guidelines reflect this shift in practice and no longer recommend postinjection antibiotics, citing strong evidence from the DRCR Network LRT trials. ${ }^{15}$ One area that still remains divided is the practice of performing same-day, bilateral injections. This survey found that $52.1 \%$ of residents are being trained to perform simultaneous, bilateral injections. In 2010, the rate among practicing physicians was reported as $46 \% .^{9}$ The new guidelines do not take a strong stance against this practice but do make sure to offer certain 
precautions. They recommend that each eye be treated as its own separate procedure and that, when possible, different lots of medications should be used for each eye. ${ }^{13}$ It has been shown that bilateral injections can be done in a safe manner that provides convenience for both the patient and the physician. ${ }^{28}$

Limitations of this study include difficulty in assessing how many residents received the survey because our method of delivery depended on the residency Program Director or Coordinator sending the survey to the ophthalmology residents. If we assume that all residents received the survey then our response rate is low. While our survey utilized previously validated questions, it was not newly validated for the resident population. A future study would benefit from a validation process that takes into consideration potential differences between the interpretations of questions by residents and attending physicians. Current practice patterns of U.S.-trained ophthalmology residents are reported in this study and it is clear that practice patterns have shifted between physicians in 2010 and residents in 2018. It is still unclear if these changes only exist in the vacuum of academic centers or if these changes have made their way to the retina community at large. Future improvements would seek to expand the response rate as well as to survey retina fellows at the beginning of their fellowship training and then again after 5 years of being in practice on their own. Ultimately, the ideal study would include residents, fellows, and physicians who have been in practice for several years. This would allow for the capture of practice patterns at the same time, and under the same set of guidelines, but across a myriad of different career points.

\section{Conclusion}

Unfortunately, there are no prior studies that assess residency training patterns that our data can be directly compared with.

The only reference points currently available are the past trends of practicing retina specialists. While this is not a direct comparison, it is the best comparison that can be drawn. It is our belief that large differences between how residents are currently trained and how physicians previously practiced can be attributed to changing guidelines. Finally, this study provides a much needed baseline to assess trends in residency training for intravitreal injections.

\section{Funding \\ None. \\ Conflict of Interest \\ None declared.}

\section{References}

1 Ramulu PY, Do DV, Corcoran KJ, Corcoran SL, Robin AL. Use of retinal procedures in medicare beneficiaries from 1997 to 2007. Arch Ophthalmol 2010;128(10):1335-1340

2 Murray TG. 2012Intravitreal injection techniques: maximizing comfort and minimizing the risk of endophthalmitis. ASRS On-Demand Webinar, September 19, 2012. Available at: http://www.asrs.org/ education/calendar/event/51/on-demand-webinar-intravitreal-injection-techniques-maximizing-comfort-and-minim. Accessed April 24, 2019

3 Fintak DR, Shah GK, Blinder KJ, et al. Incidence of endophthalmitis related to intravitreal injection of bevacizumab and ranibizumab. Retina 2008;28(10):1395-1399

4 Meyer $\mathrm{CH}$, Michels S, Rodrigues EB, et al. Incidence of rhegmatogenous retinal detachments after intravitreal antivascular endothelial factor injections. Acta Ophthalmol 2011;89(01):70-75

5 Arevalo JF, Maia M, Flynn HW Jr, et al. Tractional retinal detachment following intravitreal bevacizumab (Avastin) in patients with severe proliferative diabetic retinopathy. $\mathrm{Br} \mathrm{J}$ Ophthalmol 2008;92(02):213-216

6 Hoang QV, Mendonca LS, Della Torre KE, Jung JJ, Tsuang AJ, Freund KB. Effect on intraocular pressure in patients receiving unilateral intravitreal anti-vascular endothelial growth factor injections. Ophthalmology 2012;119(02):321-326

7 Poku E, Rathbone J, Wong R, et al. The safety of intravitreal bevacizumab monotherapy in adult ophthalmic conditions: systematic review. BMJ Open 2014;4(07):e005244

8 Scott IU, Smalley AD, Kunselman AR. Ophthalmology residency program leadership expectations of resident competency in retinal procedures and resident experience with retinal procedures. Retina 2009;29(02):251-256

9 Green-Simms AE, Ekdawi NS, Bakri SJ. Survey of intravitreal injection techniques among retinal specialists in the United States. Am J Ophthalmol 2011;151(02):329-332

10 Xing L, Dorrepaal SJ, Gale J. Survey of intravitreal injection techniques and treatment protocols among retina specialists in Canada. Can J Ophthalmol 2014;49(03):261-266

11 Anijeet DR, Hanson RJ, Bhagey J, Bates RA. National survey of the technique of intravitreal triamcinolone injection in the United Kingdom. Eye (Lond) 2007;21(04):480-486

12 Segal O, Segal-Trivitz Y, Nemet AY, Geffen N, Nesher R, Mimouni M. Survey of intravitreal injection techniques among retina specialists in Israel. Clin Ophthalmol 2016;10:1111-1116

13 Avery RL, Bakri SJ, Blumenkranz MS, et al. Intravitreal injection technique and monitoring: updated guidelines of an expert panel. Retina 2014;34(Suppl 12):S1-S18

14 American Academy of Ophthalmology. Intravitreal injections 2015. Available at: https://www.aao.org/clinical-statement/ intravitreal-injections-statement. Accessed November 28, 2018

15 Bhavsar AR, Googe JM Jr, Stockdale CR, et al; Diabetic Retinopathy Clinical Research Network. Risk of endophthalmitis after intravitreal drug injection when topical antibiotics are not required: the diabetic retinopathy clinical research network laser-ranibizumab-triamcinolone clinical trials. Arch Ophthalmol 2009;127(12):1581-1583

16 Cheung CS, Wong AW, Lui A, Kertes PJ, Devenyi RG, Lam WC. Incidence of endophthalmitis and use of antibiotic prophylaxis after intravitreal injections. Ophthalmology 2012;119(08):1609-1614

17 McCannel CA. Meta-analysis of endophthalmitis after intravitreal injection of anti-vascular endothelial growth factor agents: causative organisms and possible prevention strategies. Retina 2011; 31(04):654-661

18 Chen E, Lin MY, Cox J, Brown DM. Endophthalmitis after intravitreal injection: the importance of viridans streptococci. Retina 2011;31(08):1525-1533

19 Wen JC, McCannel CA, Mochon AB, Garner OB. Bacterial dispersal associated with speech in the setting of intravitreous injections. Arch Ophthalmol 2011;129(12):1551-1554

20 Pilli S, Kotsolis A, Spaide RF, et al. Endophthalmitis associated with intravitreal anti-vascular endothelial growth factor therapy injections in an office setting. Am J Ophthalmol 2008;145(05):879-882

21 Bhavsar AR, Stockdale CR, Ferris FL III, Brucker AJ, Bressler NM, Glassman AR; Diabetic Retinopathy Clinical Research Network. Update on risk of endophthalmitis after intravitreal drug injections and potential impact of elimination of topical antibiotics. Arch Ophthalmol 2012;130(06):809-810 
22 Storey P, Dollin M, Pitcher J, et al; Post-Injection Endophthalmitis Study Team. The role of topical antibiotic prophylaxis to prevent endophthalmitis after intravitreal injection. Ophthalmology 2014;121(01):283-289

23 Bhatt SS, Stepien KE, Joshi K. Prophylactic antibiotic use after intravitreal injection: effect on endophthalmitis rate. Retina 2011;31(10):2032-2036

24 Kim SJ, Toma HS. Antimicrobial resistance and ophthalmic antibiotics: 1-year results of a longitudinal controlled study of patients undergoing intravitreal injections. Arch Ophthalmol 2011;129(09):1180-1188
25 Dave SB, Toma HS, Kim SJ. Ophthalmic antibiotic use and multidrug-resistant staphylococcus epidermidis: a controlled, longitudinal study. Ophthalmology 2011;118(10):2035-2040

26 Aiello LP, Brucker AJ, Chang S, et al. Evolving guidelines for intravitreous injections. Retina 2004;24(5, Suppl):S3-S19

27 Willekens K, Reyns G, Diricx M, et al. Intravitreally injected fluid dispersion: importance of injection technique. Invest Ophthalmol Vis Sci 2017;58(03):1434-1441

28 Chao DL, Gregori NZ, Khandji J, Goldhardt R. Safety of bilateral intravitreal injections delivered in a teaching institution. Expert Opin Drug Deliv 2014;11(07):991-993

\section{Appendix A}

\section{Assessment of Intravitreal Injection Training Among US Based Ophthalmology Residents}

\begin{tabular}{|c|c|}
\hline $\begin{array}{l}\text { Which area of the country is your residency program } \\
\text { located in? }\end{array}$ & $\begin{array}{l}\text { Northeast } \\
\text { South } \\
\text { Midwest } \\
\text { West }\end{array}$ \\
\hline $\begin{array}{l}\text { Do you, as a resident, perform intravitreal } \\
\text { injections? }\end{array}$ & $\begin{array}{l}\text { Yes } \\
\text { No }\end{array}$ \\
\hline Where do you perform intravitreal injections? & $\begin{array}{l}\square \text { University Center } \\
\square \text { Veterans Medical Center } \\
\square \text { Community Center } \\
\square \text { Other }\end{array}$ \\
\hline \multicolumn{2}{|l|}{ Other: } \\
\hline What year of residency do you start doing injections? & $\begin{array}{l}\bigcirc \text { PGY } 2 \\
\bigcirc \text { PGY } 3 \\
\bigcirc \text { PGY } 4\end{array}$ \\
\hline $\begin{array}{l}\text { On average, how many intravitreal injections do you } \\
\text { perform each year as a resident? }\end{array}$ & $\begin{array}{l}\bigcirc<10 \\
\bigcirc 10-25 \\
25-50 \\
\bigcirc>50\end{array}$ \\
\hline $\begin{array}{l}\text { Are you trained to routinely dilate the eye that is } \\
\text { being injected prior to the injection? }\end{array}$ & $\begin{array}{l}\text { Yes } \\
\text { No }\end{array}$ \\
\hline $\begin{array}{l}\text { Are you trained to wear gloves when performing } \\
\text { intravitreal injections? }\end{array}$ & $\begin{array}{l}\text { Yes } \\
\text { No }\end{array}$ \\
\hline What types of gloves do you use? & $\begin{array}{l}\text { Clean gloves } \\
\text { Sterile gloves }\end{array}$ \\
\hline $\begin{array}{l}\text { Are you trained to use a sterile drape when } \\
\text { performing intravitreal injections? }\end{array}$ & $\begin{array}{l}\text { Yes } \\
\text { No }\end{array}$ \\
\hline $\begin{array}{l}\text { Are you trained to use a surgical face mask when } \\
\text { performing intravitreal injections? }\end{array}$ & $\begin{array}{l}\text { Yes } \\
\text { No }\end{array}$ \\
\hline $\begin{array}{l}\text { Are you trained to avoid talking in the procedure } \\
\text { room during an intravitreal injection? }\end{array}$ & $\begin{array}{l}\text { Yes } \\
\text { No }\end{array}$ \\
\hline $\begin{array}{l}\text { Are you trained to use an eyelid speculum when } \\
\text { performing intravitreal injections? }\end{array}$ & $\begin{array}{l}\text { Yes } \\
\text { No }\end{array}$ \\
\hline $\begin{array}{l}\text { Are you trained to use povidone-iodine pre-injection } \\
\text { on the conjunctiva? }\end{array}$ & $\begin{array}{l}\text { Yes } \\
\text { No } \\
\text { Other antiseptic is used }\end{array}$ \\
\hline
\end{tabular}

Other antiseptic used: 
Appendix A (Continued)

\begin{tabular}{|c|c|}
\hline $\begin{array}{l}\text { Are you trained to use povidone-iodine on the eye } \\
\text { lids? }\end{array}$ & $\begin{array}{l}\text { Yes } \\
\text { No } \\
\text { Other antiseptic is used }\end{array}$ \\
\hline \multicolumn{2}{|l|}{ Other antiseptic used: } \\
\hline $\begin{array}{l}\text { Are you trained to use prophylactic topical } \\
\text { antibiotics prior to injection? }\end{array}$ & $\begin{array}{l}\text { Yes } \\
\text { No }\end{array}$ \\
\hline $\begin{array}{l}\text { In what way are you trained to use pre-injection } \\
\text { topical antibiotics? }\end{array}$ & $\begin{array}{l}\text { Multiday course } \\
\text { Immediately prior to injection }\end{array}$ \\
\hline Which anesthetic are you trained to use? & $\begin{array}{l}\text { Topical only (eg Proparacaine/tetracaine) } \\
\text { Pledget (eg lidocaine) } \\
\text { Gel (eg lidocaine) } \\
\text { Subconjuctival } \\
\text { Other }\end{array}$ \\
\hline \multicolumn{2}{|l|}{ Other anesthetic used: } \\
\hline $\begin{array}{l}\text { Which site are you trained to prefer for your } \\
\text { injection location? }\end{array}$ & $\begin{array}{l}\text { Superotemporal } \\
\text { S Inferotemporal } \\
\text { Inferonasal } \\
\text { Superonasal }\end{array}$ \\
\hline $\begin{array}{l}\text { Are you trained to measure the distance from the } \\
\text { limbus to the injection site? }\end{array}$ & $\begin{array}{l}\text { Yes } \\
\text { No }\end{array}$ \\
\hline $\begin{array}{l}\text { How are you trained to measure the distance from the } \\
\text { limbus to the injection site? }\end{array}$ & $\begin{array}{l}\text { Calipers } \\
\text { Tuberculin syringe } \\
\text { Other }\end{array}$ \\
\hline \multicolumn{2}{|l|}{ Other type of measuring device: } \\
\hline $\begin{array}{l}\text { Are you trained to consider the speed of the jet of } \\
\text { fluid during the injection? }\end{array}$ & $\begin{array}{l}\text { Yes } \\
\text { No }\end{array}$ \\
\hline At what speed are you trained to inject the fluid? & $\begin{array}{l}\text { Slowly } \\
\text { Quickly }\end{array}$ \\
\hline $\begin{array}{l}\text { Which gauge of needle are you trained to use for the } \\
\text { injection of Anti-VEGF drugs? }\end{array}$ & $\begin{array}{l}\text { 27-gauge } \\
\text { 30-gauge } \\
\text { 31-gauge } \\
\text { Other }\end{array}$ \\
\hline \multicolumn{2}{|l|}{ Other gauge of needle used: } \\
\hline $\begin{array}{l}\text { Which gauge of needle are you trained to use for the } \\
\text { injection of triamcinolone acetonide? }\end{array}$ & $\begin{array}{l}\text { 27-gauge } \\
\text { 30-gauge } \\
\text { 31-gauge }\end{array}$ \\
\hline $\begin{array}{l}\text { Are you trained to assess post-injection optic nerve } \\
\text { perfusion? }\end{array}$ & $\begin{array}{l}\text { Yes } \\
\text { No }\end{array}$ \\
\hline $\begin{array}{l}\text { How are you trained to assess post-injection optic } \\
\text { nerve perfusion? }\end{array}$ & $\begin{array}{l}\text { Gross visual acuity exam (finger count or hand } \\
\text { motion) } \\
\text { Visualization of the optic disc } \\
\text { Measurement of intraocular pressure }\end{array}$ \\
\hline $\begin{array}{l}\text { Are you trained to use post-injection prophylactic } \\
\text { topical antibiotics? }\end{array}$ & $\begin{array}{l}\text { Yes } \\
\text { No }\end{array}$ \\
\hline $\begin{array}{l}\text { How long are you trained to use post-injection } \\
\text { prophylactic topical antibiotics? }\end{array}$ & $\begin{array}{l}\text { 1-3 days } \\
\text { 4-7 days } \\
\text { Greater than } 7 \text { days }\end{array}$ \\
\hline $\begin{array}{l}\text { Are you trained to perform bilateral simultaneous } \\
\text { intravitreal injections? }\end{array}$ & $\begin{array}{l}\text { Yes } \\
\text { No }\end{array}$ \\
\hline
\end{tabular}

